\title{
Analiza możliwości oceny stopnia deformacji plastycznej stali austenitycznych metodą magnetycznej pamięci metalu
}

\author{
Analysis of the possibility of evaluation of the \\ degree of plastic deformation of austenitic steels \\ using the metal magnetic memory testing method
}

\section{Streszczenie}

Celem badań była analiza możliwości identyfikacji obszarów odkształconych plastycznie oraz ilościowej oceny stopnia deformacji plastycznej stali austenitycznych na podstawie pomiarów własnego magnetycznego pola rozproszenia WMPR standardowymi przyrządami stosowanymi w metodzie MPM. Przedstawiono wyniki pomiarów WMPR próbek $z$ dwóch stali austenitycznych X15CrNiSi20-12 i X2CrNi18-9 o różnych stopniach trwałej deformacji. Stwierdzono, że dla stali X15CrNiSi20-12 nie występują, mierzalne standardową aparaturą metody MPM, zmiany WMPR. W przypadku stali X2CrNi18-9 obszary trwale odkształcone wyróżniają się na rozkładach składowych WMPR i jest możliwa ich identyfikacja. Opracowano ilościowe relacje pomiędzy stopniem deformacji plastycznej a wartościami gradientów. Niestety, jednoznaczne określenie stopnia deformacji możliwe jest dopiero dla dużych jej wartości, bo dopiero powyżej 10\% odkształcenia trwałego relacje stają się jednoznaczne. Ogranicza to bardzo istotnie możliwość jej praktycznego zastosowania.

\begin{abstract}
The aim of the research was to analyze the possibility of identification of areas featuring plastic strain and quantitative evaluation of the degree of plastic deformation of austenitic steels based on measurements of the residual magnetic field (RMF) with standard tools used in the metal magnetic memory testing method. Results of the RMF measurements for samples made of two grades of austenitic steel: $\mathrm{X} 15 \mathrm{CrNi}-$ Si20-12 and X2CrNi18-9 with a different degree of plastic strain are presented. It is found that for steel X15CrNiSi20-12 there are no changes in the RMF that can be measured using standard MMM testing method tools. In the case of steel $\mathrm{X} 2 \mathrm{CrNi18}-9$, the areas with plastic strain stand out in the distributions of the RMF components and their identification is possible. Quantitative relationships between the degree of plastic strain and the values of gradients are developed. Unfortunately, the degree of plastic strain can be determined unequivocally only for its large values because it is only after plastic strain exceeds $10 \%$ that the relationships become unambiguous. Consequently, the possibility of applying it in practice is substantially limited.
\end{abstract}

\section{Wstęp i cel badań}

Magnetyczna diagnostyka stanu stali austenitycznych, z racji dużego potencjału metod opartych na zmianach właściwości elektromagnetycznych tworzyw,

Dr inż. Maciej Roskosz, dr inż. Stefan Griner, mgr inż. Piotr Sosnowski - Politechnika Śląska. jest przedmiotem prac badawczych w wielu ośrodkach naukowych. Prowadzone są badania zmierzające do opracowania metod określania wpływu zmęczenia mechanicznego [1, 2], pełzania [3] oraz odkształcenia na

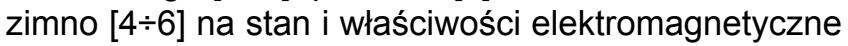
stali austenitycznych. Jako parametry diagnostyczne wykorzystuje się parametry opisujące pętlę histerezy magnetycznej, prądy wirowe, wielkości opisujące 
ilościowo szum Barkhausena oraz zmiany anizotropii właściwości elektromagnetycznych. Natężenie własnego magnetycznego pola rozproszenia WMPR, pomijając wpływ kształtu elementu, zależy od parametrów pętli histerezy magnetycznej, takich jak indukcja remanencji i pole koercji. Zmiany tych parametrów wynikają ze związków pomiędzy stanem mikrostruktury, wielkością ziaren i gęstością dyslokacji a właściwościami elektromagnetycznymi tworzyw.

W PN-ISO 24497-3 Badania nieniszczące - Magnetyczna pamięć metalu - Część 3: Kontrola złączy spawanych jest mowa o możliwości badania metodą magnetycznej pamięci metalu MPM spoin stali austenitycznych, co w pewnym stopniu zostało potwierdzone w wynikach badań przedstawionych w pracach [7, 8]. Stwierdzono, że obecność ferrytu $\delta$ w spoinie stali austenitycznej umożliwia zastosowanie metody MPM. Wartości natężenia WMPR dla spoin stali austenitycznych są dużo mniejsze niż dla spoin stali ferrytycznych. Stąd też zakłócenia zewnętrzne (źródła pola magnetycznego, blisko umiejscowione obiekty ferromagnetyczne) mogą łatwo i znacznie zniekształcić wyniki pomiarów. O obrazie magnetycznym złącza decyduje ilość i rozkład ferrytu $\delta$. Im większa jest jego ilość, a jego rozkład w spoinie bardziej równomierny, tym większe jest prawdopodobieństwo, że na obrazie WMPR zobaczymy zakłócenia spowodowane występowaniem wad. W przypadku nierównomiernego rozkładu ferrytu $\delta$ w złączu, rozkład WMPR jest często bardziej obrazem tej nierównomierności, niż wynikiem występowania wad.

Na skutek odkształceń plastycznych w stalach austenitycznych mogą pojawić się fazy magnetyczne. Celem badań przedstawionych w niniejszym artykule była analiza możliwości identyfikacji obszarów odkształconych plastycznie oraz ilościowej oceny stopnia deformacji plastycznej na podstawie pomiarów własnego magnetycznego pola rozproszenia standardowymi przyrządami stosowanymi w metodzie MPM.

\section{Przemiany struktur stali austenitycznych}

W wysokostopowych stalach chromowo-niklowych typu 18-8, zależnie od stężenia $\mathrm{Cr}$ i $\mathrm{Ni}$ oraz innych dodatków stopowych, w temperaturze pokojowej występuje struktura austenityczna, może też pojawiać się pewna zawartość ferromagnetycznego ferrytu $\delta$. Strukturę stali można dość dobrze ocenić na podstawie składu chemicznego, posługując się równoważnikami pierwiastków austenitotwórczych i ferrytotworczych. W tym przypadku wykorzystuje się wykresy Schaefflera, De Longa, Hulla oraz inne.

Stale austenityczne Fe-Cr-Ni po przesycaniu zachowują w temperaturze otoczenia bazową strukturę austenityczną o sieci regularnej płaskocentrycznej $(\gamma)$.
Zależnie od składu chemicznego austenit taki może być fazą metastabilną ulegającą przemianie martenzytycznej przy ochłodzeniu poniżej temperatury $\mathrm{M}_{\mathrm{s}}$ lub pod wpływem krytycznego odkształcenia plastycznego przy temperaturach wyższych od $\mathrm{M}_{\mathrm{s}}$. Stale austenityczne są materiałami powszechnie stosowanymi, a występująca w nich odkształceniowa przemiana martenzytyczna może mieć zarówno pozytywne następstwa, powodując umocnienie materiału, jak i niepożądane, powodując spadek odporności na korozję oraz pojawienie się fazy ferromagnetycznej $[9 \div 14]$.

Austenityczne stale chromowo-niklowe pod wpływem odkształcenia plastycznego na zimno ulegają znacznemu umocnieniu, zależnie od składu chemicznego, wielkości gniotu i temperatury odkształcenia. Pod wpływem odkształcenia plastycznego na zimno następuje zmiana struktury dyslokacyjnej, w wyniku czego metastabilny austenit przechodzi częściową przemianę w martenzyt $\varepsilon$ oraz ferromagnetyczny martenzyt $\alpha$ o strukturze regularnej przestrzennie centrowanej [12:14]. Podobna przemiana dla stali austenitycznych zachodzi podczas oziębiania do niskich temperatur. Uważa się, że przemianie tej odpowiadają dwa możliwe mechanizmy [15]: pierwszy dotyczy przemiany typu: $\gamma$ $\rightarrow \varepsilon \rightarrow \alpha^{\prime}$, gdzie faza $\varepsilon$ jest fazą pośrednią o strukturze heksagonalnej gęsto upakowanej, a drugi - przemiany bezpośredniej $\gamma \rightarrow \alpha$ ' oraz niezależnie $\gamma \rightarrow \varepsilon$. Czynnikiem decydującym o możliwości powstawania martenzytu $\varepsilon$ jest energia błędu ułożenia austenitu (EBU), która zależy od składu chemicznego stali i temperatury odkształcania. Martenzyt $\varepsilon$ może powstawać podczas odkształcenia plastycznego na zimno, jeżeli EBU w temperaturze pokojowej jest < $30 \mathrm{MJm}^{-2}$ [16]. EBU decyduje o występującym systemie odkształcenia (poślizgu), który umożliwia tworzenie fazy pośredniej $\varepsilon$ lub prowadzi bezpośrednio do tworzenia fazy $\alpha$ '. W stalach o wyższej EBU, gdzie występuje podstawowy system odkształcenia austenitu typu \{111\} [1T̄0] nie obserwuje się powstania fazy $\varepsilon$. Wykazano jednak, że zależnie od warunków odkształcenia, w tej samej stali przemiana może zachodzić bezpośrednio lub z udziałem fazy pośredniej. Pierwiastkiem, który silnie hamuje przemianę $\gamma \rightarrow \varepsilon$, jest nikiel. W tym przypadku przemiana austenitu w martenzyt zachodzi bezpośrednio $\gamma \rightarrow \alpha^{\prime}[14,15]$.

\section{Szczegóły badań}

Badano próbki płytowe ze stali austenitycznych X15CrNiSi20-12 (EN 10095, grupa materiałowa 1.4828) oraz X2CrNi18-9 (EN 10088-1, grupa materiałowa 1.4307). Skład chemiczny materiałów próbek podano w tablicy I. Geometrię badanych próbek przedstawiono na rysunku 1. Uzyskane podczas badań relacje pomiędzy odkształceniem $\varepsilon$ a rozciągającymi naprężeniami inżynierskimi $\sigma$ pokazano na rysunku $2 a$ dla stali $\mathrm{X} 15 \mathrm{CrNiSi} 20-12$ oraz na rysunku $2 \mathrm{~b}$ dla stali X2CrNi18-9. 
Tablica I. Skład chemiczny badanych stali

Table I. Chemical composition of steel grades under analysis

\begin{tabular}{|c|c|c|c|c|c|c|c|c|c|c|c|}
\hline \multirow{3}{*}{ Oznaczenie stali } & \multicolumn{11}{|c|}{$\%$ masy } \\
\hline & C & $\mathrm{Si}$ & $\mathrm{Mn}$ & $\mathrm{P}$ & \multirow{2}{*}{ S } & $\mathrm{N}$ & \multirow{2}{*}{$\mathrm{Cr}$} & \multirow{2}{*}{ Mo } & \multirow{2}{*}{$\mathrm{Nb}$} & \multirow{2}{*}{$\mathrm{Ni}$} & \multirow{2}{*}{$\mathrm{Ti}$} \\
\hline & $\max$ & $\max$ & $\max$ & $\max$ & & $\max$ & & & & & \\
\hline X15CrNiSi20-12 & $\leq 0,20$ & $\begin{array}{c}1,50 \\
\div 2,50\end{array}$ & $\leq 2,00$ & 0,045 & 0,015 & $\leq 0,11$ & $\begin{array}{c}19,0 \\
\div 21,0\end{array}$ & - & - & $\begin{array}{c}11,0 \\
\div 13,0\end{array}$ & - \\
\hline X2CrNi18-9 & 0,02 & 0,45 & 1,43 & 0,031 & 0,008 & - & 18 & 0,3 & 0,017 & 7,94 & 0,01 \\
\hline
\end{tabular}

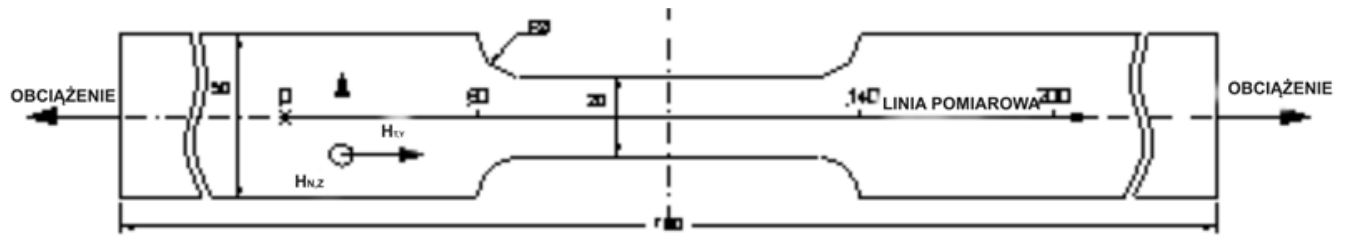

Rys. 1. Próbka do badań

Fig. 1. Experimental sample

Skład fazowy badanych stali określono, posługując się kryteriami Schaefflera, dzięki którym na podstawie składu chemicznego stali można obliczyć równoważnik chromu, jako główny składnik ferrytotwórczy, oraz równoważnik niklu, jako główny składnik austenitotwórczy. Z wykresu Schaefflera odczytano, że stal X15CrNiSi20-12 ma strukturę austenityczną, stal X2CrNi18-9 strukturę austenityczną z udziałem ferrytu i martenzytu (przy szybkim chłodzeniu dla spoin).

Badane próbki były obciążane za pomocą maszyny wytrzymałościowej Galdabini Sun 10P. Po osiągnięciu zadanych obciążeń próbki były odciążane i badane poza maszyną. Jako miarę odkształcenia plastycznego $\varepsilon$ przyjęto odkształcenie plastyczne próbki badane na odcinku pomiędzy 60. a 140. punktem pomiarowym, pierwotnie o długości $80 \mathrm{~mm}$ (rys. 1).

Do badań wykorzystywano magnetometr TSC-1M-4 z głowicą pomiarową TSC-2M dostarczony przez Energodiagnostika Co. Ltd Moscow. Aparatura pomiarowa została wykalibrowana w polu magnetycznym Ziemi do założonej wartości $40 \mathrm{~A} / \mathrm{m}$. Pomiary prowadzono zawsze na stanowisku w tym samym miejscu, przy takim samym położeniu próbki. Składowe pola magnetycznego w miejscu wykonywania pomiarów miały wartości $\mathrm{H}_{\mathrm{T}, \mathrm{X}}=8 \mathrm{~A} / \mathrm{m}, \mathrm{H}_{\mathrm{T}, \mathrm{Y}}=8 \mathrm{~A} / \mathrm{m}, \mathrm{H}_{\mathrm{N}, \mathrm{Z}}=40 \mathrm{~A} / \mathrm{m}$. Pomiary natężenia pola magnetycznego wykonywano wzdłuż linii pomiarowej w 200 punktach (rys. 1). Odległości między tymi punktami w stanie początkowym wynosiły $1 \mathrm{~mm}$ i zwiększały się odpowiednio wraz ze wzrostem odkształcenia plastycznego.

Mierzono dwie składowe WMPR na powierzchni próbki (rys. 1):

- $\mathrm{H}_{T, Y}$ - składowa styczna mierzona w kierunku równoległym do kierunku zadawanego obciążenia,

- $\mathrm{H}_{\mathrm{NZ}}$ - składowa normalna.

W prowadzonych badaniach kierunek pola magnetycznego (pole magnetyczne Ziemi) nie był współosiowy z kierunkiem zadawanych obciążeń rozciągających oraz powstałych na skutek nierównomiernych odkształceń plastycznych naprężeń resztkowych.
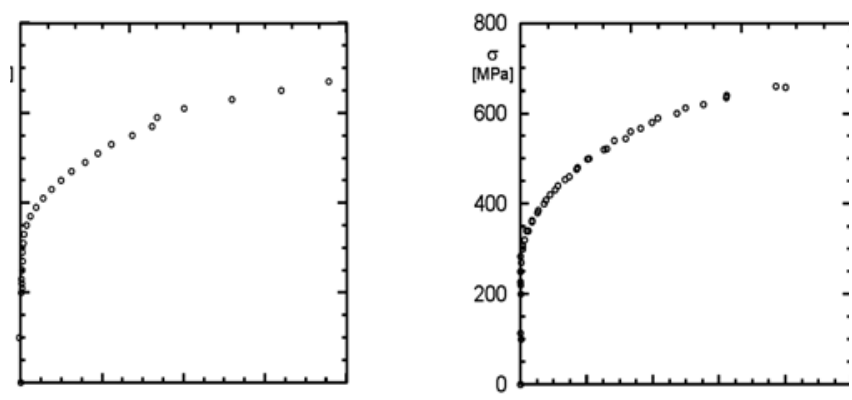

Rys. 2. Relacje pomiędzy odkształceniem trwałym $\varepsilon$ a rozciagajacymi naprężeniami inżynierskimi $\sigma$ dla badanych stali austenitycznych: a) stal $\mathrm{X} 15 \mathrm{CrNiSi} 20-12$, b) stal $\mathrm{X} 2 \mathrm{CrNi18-9}$

Fig. 2. Relationship between plastic strain $\varepsilon_{p}$ and engineering tensile stress 6 for austenitic steels under analysis: a) X15CrNiSi20-12 steel, b) X2CrNi18-9 steel

\section{Wyniki badań i dyskusja}

Przykładowe rozkłady składowych WMPR badanych próbek dla stanu początkowego i dla znacznych odkształceń plastycznych pokazano dla stali X15CrNiSi20-12 na rysunkach 3 a i 3 b oraz na rysunkach $4 a$ i $4 b$ dla stali X2CrNi18-9.

$\mathrm{Na}$ rysunkach $3 \mathrm{a}$ i $3 \mathrm{~b}$ widać, że zmiany wartości składowych WMPR pomiędzy stanem początkowym a stanem dla $40 \%$ odkształcenia plastycznego są minimalne w granicy niepewności pomiaru. Odkształcony plastycznie obszar próbki w ogóle nie jest widoczny na rozkładach składowych WMPR. Wynika z tego, że dla stali X15CrNiSi20-12 ocena stopnia deformacji plastycznej na podstawie WMPR jest praktycznie niemożliwa.

Interesująco wyglądają natomiast rozkłady składowych WMPR dla próbek ze stali X2CrNi18-9. Widoczna jest wyraźna różnica wartości składowych WMPR pomiędzy stanem początkowym a stanem znacznego odkształcenia plastycznego (rys. 4a i 4b). Obszar odkształcony plastycznie (obszar próbki o mniejszym przekroju, leżący pomiędzy 40. a 160. punktem 
pomiarowym) jest wyraźnie widoczny na rozkładach obydwu analizowanych składowych WMPR. Na granicach tego obszaru występują ekstrema w rozkładach składowych. W samym obszarze odkształconym plastycznie zarówno składowa styczna $\mathrm{H}_{\mathrm{T}, \text { }}$, jak i składowa normalna $\mathrm{H}_{\mathrm{N}, \mathrm{z}}$ przyjmują zdecydowanie inne wartości i mają inny trend zmian niż w pozostałej części próbki.

Ze względu na dużą zmienność wartości składowych WMPR w obszarze odkształconym plastycznie w dalszej analizie wyników pomiarów zmierzającej do opracowania relacji diagnostycznej skupiono się nad analizą gradientów składowych WMPR. Gradienty zmian składowych WMPR (rozumiane jako wartości bezwzględne pochodnych funkcji) wyznaczono przez aproksymację odcinkową wyników pomiarów funkcjami sklejanymi 3 stopnia. Przykładowe rozkłady gradientów, odpowiadające rozkładom składowych WMPR przedstawionych na rysunkach $4 a$ i $4 b$, pokazano na rysunkach $5 \mathrm{a}$ i $5 \mathrm{~b}$. W rozkładzie gradientów dominują dwa maksima w strefach zmiany przekroju.

Analizowano wpływ stopnia odkształcenia plastycznego na wartości maksymalne gradientów składowych WMPR, które występują w strefach zmiany przekroju, oraz na wartości średnie gradientów składowych WMPR wyznaczone dla obszaru o stałym przekroju na odcinku pomiędzy 90. a 110. punktem na linii pomiarowej próbki (rys. 1). a)

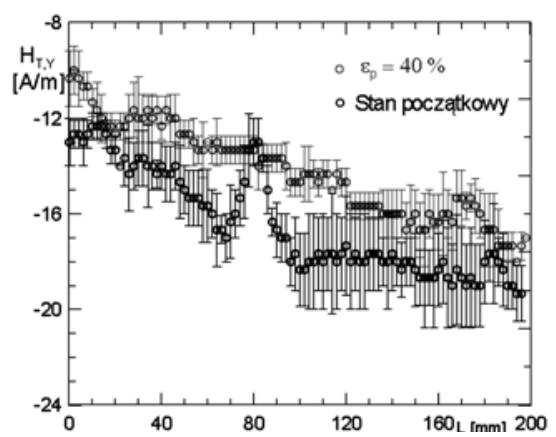

b)

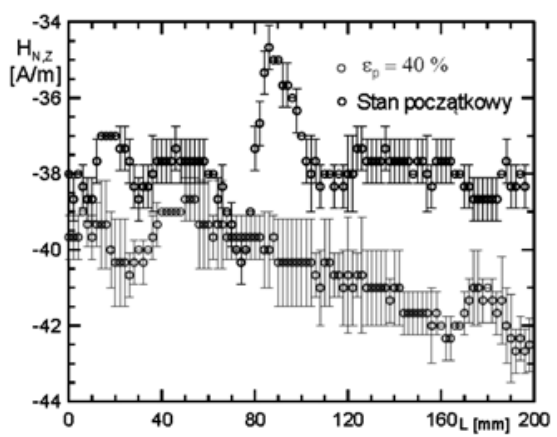

Rys. 3. Rozkłady składowych WMPR w stanie początkowym i w stanie znacznego odkształcenia plastycznego dla stali X15CrNiSi20-12: a) składowa styczna $\mathrm{H}_{\mathrm{T}, \mathrm{Y}}$, b) składowa normalna $\mathrm{H}_{\mathrm{N}, \mathrm{Z}}$

Fig. 3. Distributions of the RMF components in the initial state and in the state of considerable plastic deformation for $\mathrm{X} 15 \mathrm{CrNiSi} 20-12$ steel: a) tangential component $H_{T, Y}$, b) normal component $H_{N, Z}$

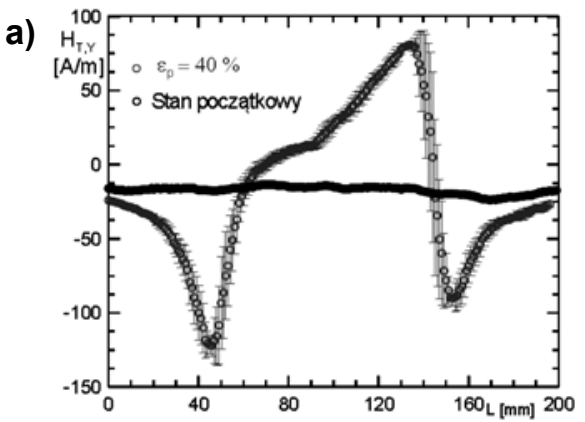

b)

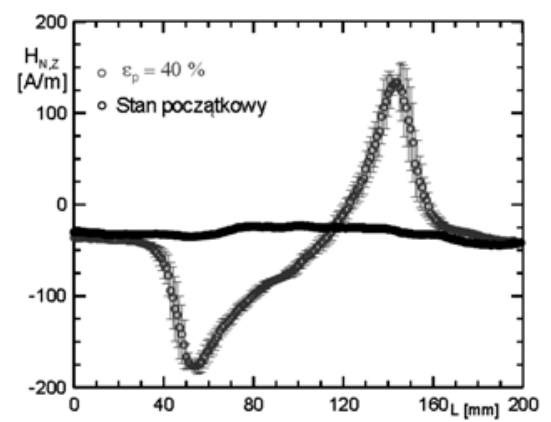

Rys. 4. Rozkłady składowych WMPR w stanie początkowym i w stanie znacznego odkształcenia plastycznego dla stali X2CrNi18-9: a) składowa styczna $\mathrm{H}_{\mathrm{TY}}$; b) składowa normalna $\mathrm{H}_{\mathrm{NZ}}$

Fig. 4. Distributions of the RMF components in the initial state and in the state of considerable plastic deformation for $\mathrm{X} 2 \mathrm{CrNi18}-9$ steel: a) tangential component $\mathrm{H}_{T, Y}$; b) normal component $\mathrm{H}_{\mathrm{N}, \mathrm{Z}}$

a)

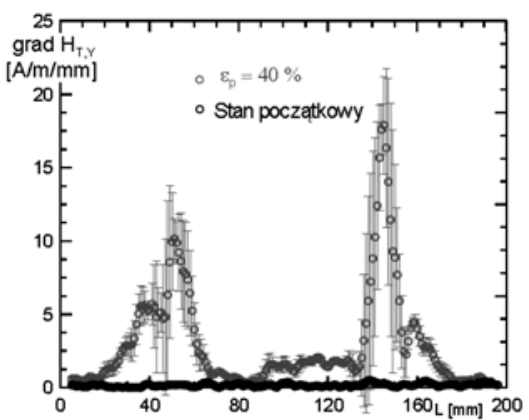

b)

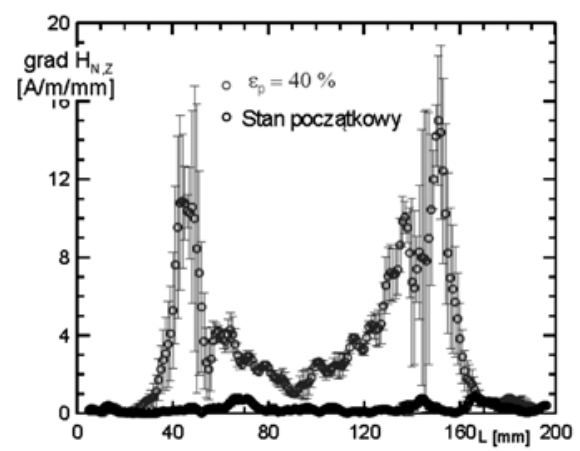

Rys. 5. Rozkłady gradientów składowych WMPR w stanie początkowym i w stanie znacznego odkształcenia plastycznego dla stali X2CrNi18-9: a) gradient składowej stycznej grad $\mathrm{H}_{\mathrm{T}, \mathrm{Y}}$; b) gradient składowej normalnej grad $\mathrm{H}_{\mathrm{N}, \mathrm{Z}}$

Fig. 5. Distributions of gradients of the RMF components in the initial state and in the state of considerable plastic deformation for X2CrNi18-9 steel: a) tangential component gradient grad $\mathrm{H}_{\mathrm{T}, \mathrm{Y}} ;$ b) normal component gradient grad $\mathrm{H}_{\mathrm{N}, \mathrm{Z}}$ 
Wyznaczone dla próbek ze stali X2CrNi18-9 relacje pomiędzy stopniem trwałej deformacji a maksymalnymi gradientami składowych WMPR pokazano na rysunkach $6 a$ i $6 \mathrm{~b}$ a relacje pomiędzy stopniem trwałej deformacji a średnimi gradientami składowych WMPR na rysunkach $7 \mathrm{a}$ i $7 \mathrm{~b}$. Wraz ze wzrostem stopnia deformacji rosną zarówno wartości maksymalne jak i średnie gradientów składowych WMPR. Niestety, dla badanej stali X2CrNi18-9 widać, że w miarę jednoznaczne zależności pomiędzy stopniem odkształcenia plastycznego a wartościami gradientów WMPR występują dopiero po przekroczeniu wartości $10 \%$ odkształcenia plastycznego. Dla mniejszych wartości odkształcenia plastycznego wartości gradientów nie ulegają obserwowalnym zmianom.
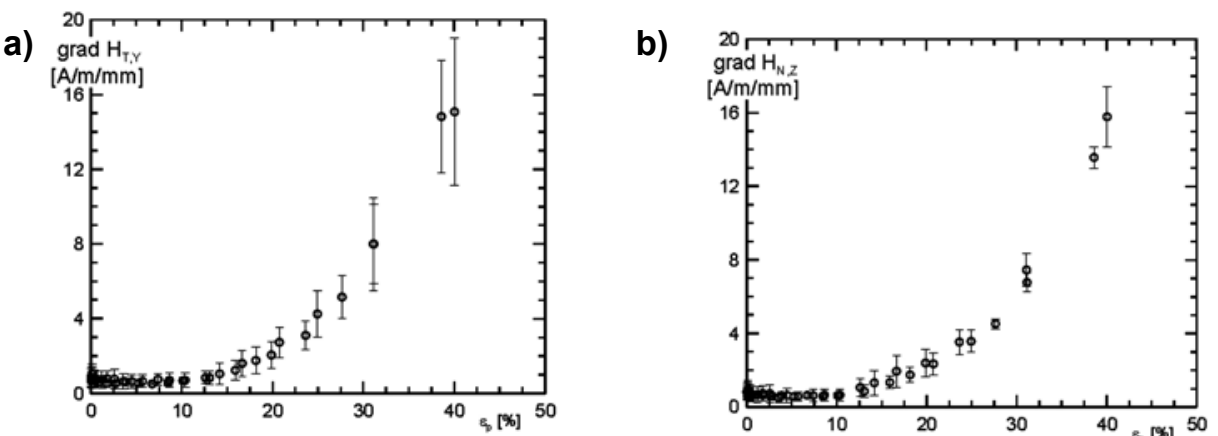

Rys. 6. Relacje pomiędzy stopniem trwałej deformacji a gradientami maksymalnymi w miejscu zmiany przekroju dla stali X2CrNi18-9: a) gradient składowej stycznej grad $\mathrm{H}_{\mathrm{T}, \mathrm{Y}}$, ) gradient składowej normalnej grad $\mathrm{H}_{\mathrm{N}, \mathrm{Z}}$

Fig. 6. Relationships between the degree of plastic strain and the maximum gradients in the area of change in the cross section for $\mathrm{X} 2 \mathrm{CrNi18}-9$ steel: a) tangential component gradient grad $\mathrm{H}_{\mathrm{T}, \mathrm{r}}$, b) normal component gradient grad $\mathrm{H}_{\mathrm{N}, \mathrm{Z}}$
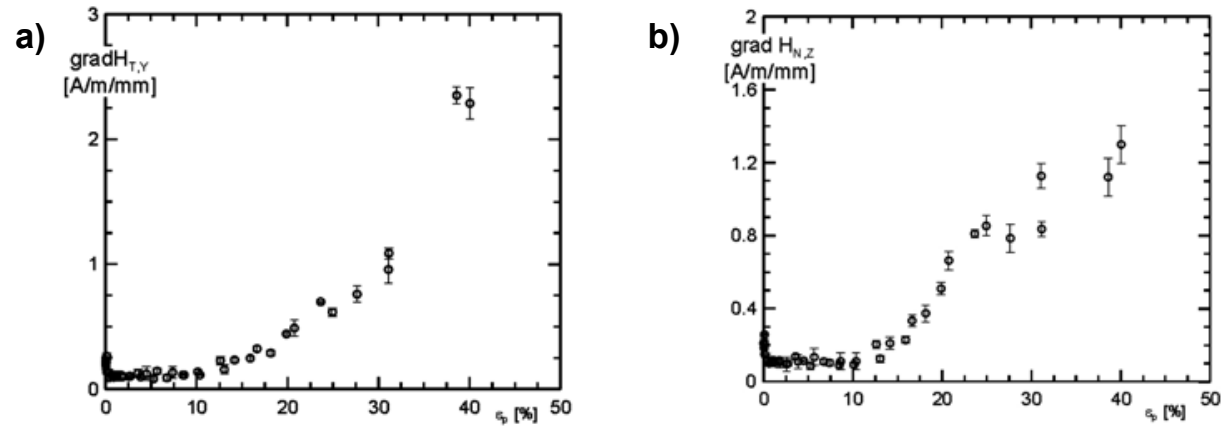

Rys. 7. Relacje pomiędzy stopniem trwałej deformacji a gradientami średnimi dla stali X2CrNi18-9: a) gradient składowej stycznej grad $\mathrm{H}_{\mathrm{T}, \gamma^{\prime}}$ b) gradient składowej normalnej grad $\mathrm{H}_{\mathrm{N}, \mathrm{Z}}$

Fig. 7. Relationships between the degree of plastic strain and the average gradients for $\mathrm{X} 2 \mathrm{CrNi18}-9$ steel: a) tangential component gradient grad $\mathrm{H}_{\mathrm{T}, \mathrm{r}}$ b) normal component gradient grad $\mathrm{H}_{\mathrm{N}, \mathrm{Z}}$

\section{Podsumowanie}

Przedstawiono wyniki pomiarów metodą magnetycznej pamięci metalu MPM próbek $z$ dwóch stali austenitycznych, X15CrNiSi20-12 i X2CrNi18-9 o różnych stopniach trwałej deformacji. Stwierdzono, że dla stali X15CrNiSi20-12 nie występują, mierzalne standardową aparaturą metody MPM, zmiany wartości sygnału diagnostycznego - natężenia własnego magnetycznego pola rozproszenia WMPR. W przypadku stali X2CrNi18-9 obszary trwale odkształcone wyróżniają się na rozkładach składowych WMPR i jest możliwa ich identyfikacja. Opracowano ilościowe relacje pomiędzy stopniem deformacji plastycznej a wartościami gradientów. Niestety, jednoznaczne określenie stopnia deformacji możliwe jest dopiero dla dużych wartości, bo dopiero powyżej $10 \%$ odkształcenia trwałego relacje stają się jednoznaczne. Ogranicza to bardzo istotnie możliwość jej praktycznego zastosowania.
Istotne znaczenie w diagnostyce i zmianach sygnału pomiarowego badanych stali austenitycznych ma obecność i zmiany ilościowe tworzącej się fazy ferromagnetycznej podczas odkształcenia plastycznego. W stali X2CrNi18-9 faza ferromagnetyczna - ferryt $\delta$ w niewielkiej ilości występuje już w stanie nieodkształconym, a następnie w miarę wzrostu odkształcenia i po przekroczeniu pewnego odkształcenia krytycznego występuje wyraźny przyrost sumarycznego udziału faz ferromagnetycznych na skutek występowania przemiany martenzytycznej i tworzenia martenzytu $\alpha$ '.

Przedstawione wyniki badań nie wyczerpują tematu, lecz zaledwie go zarysowują. Być może dla innych gatunków stali austenitycznych okaże się możliwe opracowanie tego typu zależności diagnostycznych. Należy wówczas pamiętać o czynnikach wpływających na relacje ilościowe w metodzie MPM, takich jak położenie w polu magnetycznym Ziemi oraz wielkość i kształt badanych elementów. 


\section{Literatura}

[1] Żurek Z. H., Sieradzki S., Adamek J.: Ocena stanu technicznego kołpaków generatorów na podstawie pomiarów magnetycznych niestabilności austenitu dla stali G18H18, Przegląd Spawalnictwa (13), 2011, s. 8-12.

[2] Vincent A. i in.: Magnetic Barkhausen noise from straininduced martensite during low cycle fatigue of $304 \mathrm{~L}$ austenitic stainless steel, Acta Materialia 53 (2005), 4579-4591.

[3] Augustyniak B., Chmielewski M., Sablik M.J., Augustyniak M., Walker S.: A new eddy current method for nondestructive testing of creep damage in austenitic boiler tubing, Nondestructive Testing and Evaluation 24 (1-2) 2009, s. 121-141

[4] Novotny P., Macha P., Sajdl P., Diagnostics of austenitic steels by coercivity mapping, NDT\&E International 41 (2008), 530- 533.

[5] O'Sullivan D., Cotterell M., Meszaros I.: The characterisation of work-hardened austenitic stainless steel by NDT micromagnetic techniques, NDT\&E International 37 (2004) 265269.

[6] Meszaros I., Prohaszka J.: Magnetic investigation of the effect of a-martensite on the properties of austenitic stainless steel, Journal of Materials Processing Technology 161 (2005), 162-168.

[7] Roskosz M.: Metal magnetic memory testing of welded joints of ferritic and austenitic steels, NDT\&E International 44 (2011) 305-310, doi:10.1016/j.ndteint.2011.01.008.

[8] Roskosz M., Griner S., Staniek D., Bonik A.: Badania połączeń spawanych stali austenitycznych metodą magnetycznej pamięci metalu. 39 Krajowa Konferencja Badań Nieniszczących, Szczyrk 2010.

\section{Podziękowanie}

Przedstawione $w$ artykule wyniki zostały uzyskane $w$ badaniach współfinansowanych przez Narodowe Centrum Badań $i$ Rozwoju w ramach umowy SP/E/1/67484/10 - Strategiczny Program Badawczy - Zaawansowane technologie pozyskiwania energii: Opracowanie technologii dla wysokosprawnych „zeroemisyjnych” bloków węglowych zintegrowanych z wychwytem $\mathrm{CO}_{2}$ ze spalin.
[9] Echigoya J., Ueda T., Li X.: Martensitic transformation due to plastic deformation and magnetic properties in SUS 304 stainless steel, Journal of Materials Processing Technology 108 (2001), s. 213-216.

[10] Babiński W., Griner S.: Badania drutów ze stali austenitycznych chromowo-niklowych przeznaczonych na sita tkane, Prace Instytutu Efektywności Wykorzystania Materiałów, 1/2, 1980 , s. 25.

[11] Nagy E., Mertinger V., Tranta F.,Sólyom J.: Deformation induced martensitic transformation in stainless steels, Materials Science and Engineering A 2004, s. 308-313.

[12] Hong Chul Shin, Tae Kwon Ha, Young Won Chang: Kinetics of deformation induced martensitic transformation in a 304 stainless steel, Scripta Materialia 2001, s. 823-829.

[13] Milad M., Zreiba N., Elhalouanin F.: The effect of cold work on structure and properties of AISI 304 stainless steel, Journal of Materials Processing Technology 203 (2008), s. 80-85.

[14] Cina B.: Effect of Cold Working on the g-a Transformation In Some Fe-Ni-Cr Alloys. Journal of the Iron and Steel Institute 1977, 1954, 406.

[15] Blanc G., Tricot R.: Transformations martensitiques dens les aciers inoxydables austenitiques $\mathrm{Fe}-\mathrm{Cr}-\mathrm{Ni}$, Mem. Sci. Rev. Metall. 7-8, 1973, 527

[16] Adamczyk J., Szkaradek K.: Materiały metalowe dla energetyki jądrowej, Wyd. Pol. Śl. Gliwice 1992, 236L.

\section{Wykaz firm współpracujących z redakcją Przeglądu Spawalnictwa w 2013 r.}

\section{zeszyt}

4metal.pl

Abicor Binzel

$2,4,6,8,10,12$

$6,10,12$

Cloos Polska

$2,4,6,8,10,12$

Draco

$\ldots$

Esab

Figel

Instytut Spawalnictwa w Gliwicach

Kemppi

$2,4,6,8,10,12$

Koli

Lincoln Electric Bester

Linde Gaz Polska

Messe Essen
NDT Test

Pemamek

PoliTest

Rywal-RHC

SIMP ODK w Szczecinie

Solidtech

Spaw-Tech

Stanley CRC-Evans

Technika Spawalnicza w Poznaniu .............................. 1, 5

Testing

Urząd Dozoru Technicznego

zeszyt 12 